\title{
Pseudotumoral presentation of primary central nervous system vasculitis
}

\author{
Vasculite do sistema nervoso central na forma pseudotumoral \\ Tatiana Goyanna Lyraํ, Maria da Graça Morais Martin², Rodrigo do Carmo Carvalho³, Claudia Regina Gomes \\ Cardim Mendes Oliveira ${ }^{4}$, Luis Filipe de Souza Godoy5, Daniel de Sousa Delgado5, Giovanni Guido Cerri ${ }^{6}$, \\ Claudia da Costa Leite? \\ ${ }^{1}$ Médica residente de Radiologia do Hospital Sírio Libanês, São Paulo SP, Brazil; \\ ${ }^{2}$ Médica neurorradiologista do Hospital Sírio Libanês e do Hospital das Clínicas da Faculdade de Medicina da Universidade de São Paulo (HCFM-USP), \\ São Paulo SP, Brazil; \\ ${ }^{3}$ Médico neurologista do Hospital Sírio Libanês, São Paulo SP, Brazil; \\ ${ }^{4}$ Doutora em Patologia pela Faculdade de Medicina da Universidade de São Paulo (USP), Médica patologista do Hospital Sírio Libanês e do Grupo Fleury, \\ São Paulo SP, Brazil; \\ ${ }^{5}$ Médicos neurorradiologistas do Hospital Sírio Libanês, São Paulo SP, Brazil; \\ ${ }^{6}$ Titular do Departamento de Radiologia pela Faculdade de Medicina da Universidade de São Paulo (USP), Chefe da Radiologia do Hospital Sírio Libanês e \\ Secretário de Saúde do Estado de São Paulo, São Paulo SP, Brazil; \\ ${ }^{7}$ Professora-Associada do Departamento de Radiologia da Faculdade de Medicina da Universidade de São Paulo (USP), Médica pesquisadora do Instituto de \\ Ensino e Pesquisa (IEP) do Hospital Sírio Libanês, São Paulo SP, Brazil. \\ Correspondence: Tatiana Goyanna Lyra; Rua Frei Caneca 750 / apto. 1.052; 01307-000 São Paulo SP - Brasil; E-mail: tatigoyanna@hotmail.com \\ Conflict of interest: There is no conflict of interest to declare. \\ Received 21 August 2012; Received in final form 27 November 2012; Accepted 04 December 2012.
}

\section{CASE REPORT}

A 28-year-old man, with insidious and progressive onset of semantic and phonemic aphasia, associated with evolving numbness and loss of sensation over weeks. Magnetic resonance imaging (MRI) revealed T2-hyperintense expansive lesions, heterogeneous contrast enhancement, and no diffusion restriction in subcortical regions on the left parietal and temporal lobes, right superior parietal lobe, post-central gyrus and splenium of corpus callosum, with perilesional edema and hemorrhagic foci. Steroid and cyclophosphamide pulses were introduced and stabilized the clinical symptoms.

One month later, a new MRI (Fig 1) showed improvement of the expansive effect, edema and enhancement of the lesions. Magnetic resonance angiography (MRA) and digital subtraction angiography (DSA) presented only a subtle enhancement in the capillary-venous phase in the left frontal and parietal lobes.

The brain biopsy was performed and revealed postischemic necrosis associated with nonspecific perivascular lymphomonocytic infiltrate with predominance of
$\mathrm{T}$ lymphocytes without atypias. Immunohistochemistry showed small numbers of mature perivascular lymphocytes, CD20+, CD3+ and CD68+ cells, which are compatible with lymphocytic vasculitis. Clinical and pathological picture was compatible with primary lymphocytic angiitis of the central nervous system (PLACNS).

Corticosteroid (1 g/day) and cyclophosphamide (1 g/day) pulse therapy was introduced for three days and repeated monthly during three months. Prednisone $(20 \mathrm{mg} /$ day $)$ was introduced as maintenance therapy, and resulting in improved clinical outcomes and MRI imaging. In the fifth month, the patient presented worsening of the sensitive symptoms and developed new MRI lesions (Fig 2).

New corticosteroid and cyclophosphamide pulse therapy was introduced for three months, resulting in almost complete resolution of the symptoms and improvement of MRI findings. Prednisone $40 \mathrm{mg} /$ day was introduced, but no improvement in the MRI was observed. Later, azatioprine $(50 \mathrm{mg} /$ day) was associated with the therapy. A oneyear follow-up MRI showed significant improvement of the lesions (Fig 3). 


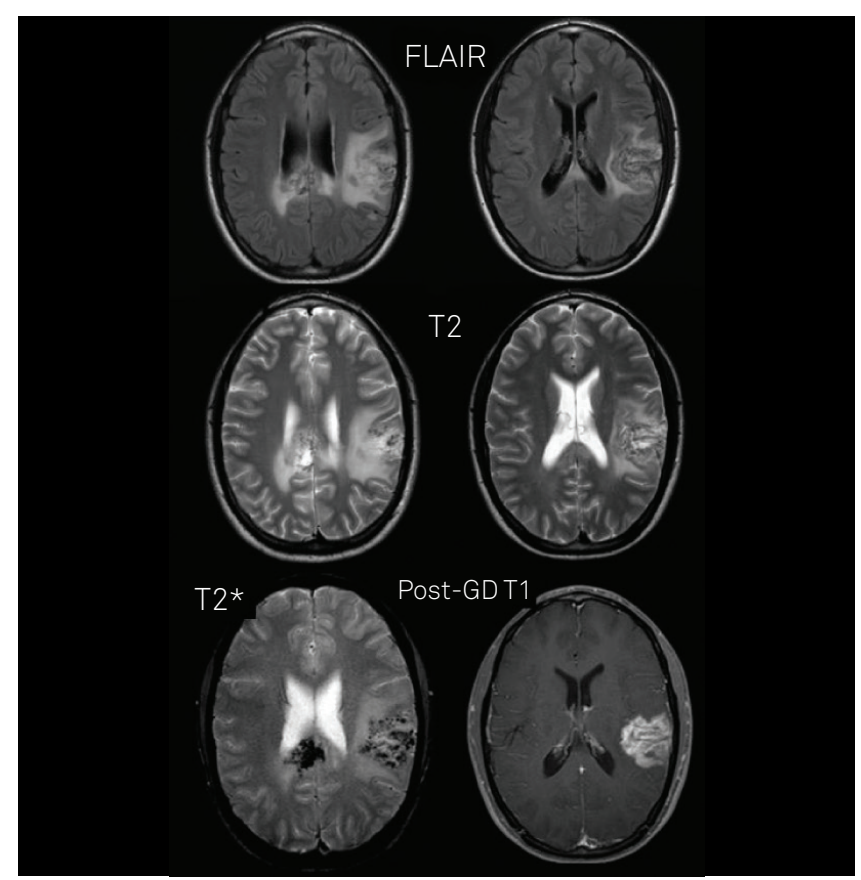

Fig 1. Brain magnetic resonance imaging one month after the onset of clinical symptoms and corticosteroid therapy. Expansive lesions were detected in left cortical/subcortical parietal lobe and in the splenium of the corpus callosum. The lesions presented heterogeneous hyperintense signal on FLAIR and T2-weighted images, marked hypointense signal on T2* (blood products), and contrast enhancement (blood brain barrier disruption). Perilesional edema was also noted. The other brain lesions detected presented the same signal intensity (not shown).

\section{DISCUSSION}

PLACNS is a rare inflammatory vasculitis that affects the parenchyma and meningeal arteries and veins ${ }^{1-4}$. An even less common subtype of PLACNS is the lymphocytic vasculitis ${ }^{1,5}$. Pseudotumoral presentation corresponds to 5\% of PLANCS. The pathogenesis, diagnosis, and treatment of the disease are challenging with few reports in the literature ${ }^{3,5}$. Its cause remains unclear, but a viral etiology, as well as an association with lymphoma, has been suggested ${ }^{1,3}$. If not treated, progressive neurological decline or even death may occur ${ }^{1,4}$.

PLANCS is usually diagnosed by exclusion based on radiological, pathological, and immunohistochemical findings $\mathrm{s}^{5-7}$. Three main histological patterns have been reported, the granulomatous inflammatory pattern, the lymphocytic pattern, and the acute necrotizing one ${ }^{3,8}$.

MRI, MRA, and DSA can help in the diagnosis ${ }^{1,4}$. Proton spectroscopy can help excluding other pathologies in case of pseudotumoral form ${ }^{1}$. MRI findings are almost always present, but they are inespecific ${ }^{2}$. Diffuse white matter lesions and microangiopathy are commonly observed ${ }^{2,6,9}$. Despite a positive biopsy, DSA can be normal if small brain vessels are affected ${ }^{4,9}$. On the other hand, a negative biopsy cannot exclude vasculitis ${ }^{4}$. When clinical and MRI findings

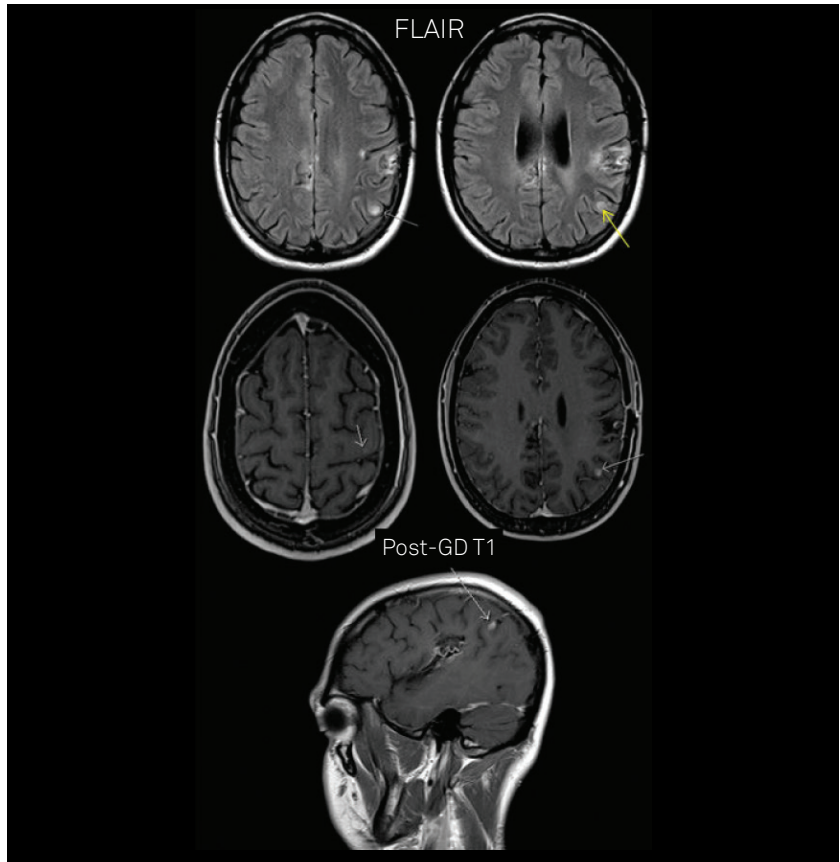

Fig 2. Five months after the onset of symptoms (one month after corticosteroid-cyclophosphamide pulse therapy), the patient presented clinical worsening. New enhancement foci were detected in the left pre and post-central gyri. The initial parietal lesion present on this examination decreased in size, and the enhancement and perilesional edema decreased when compared to the prior examination (Fig 1).

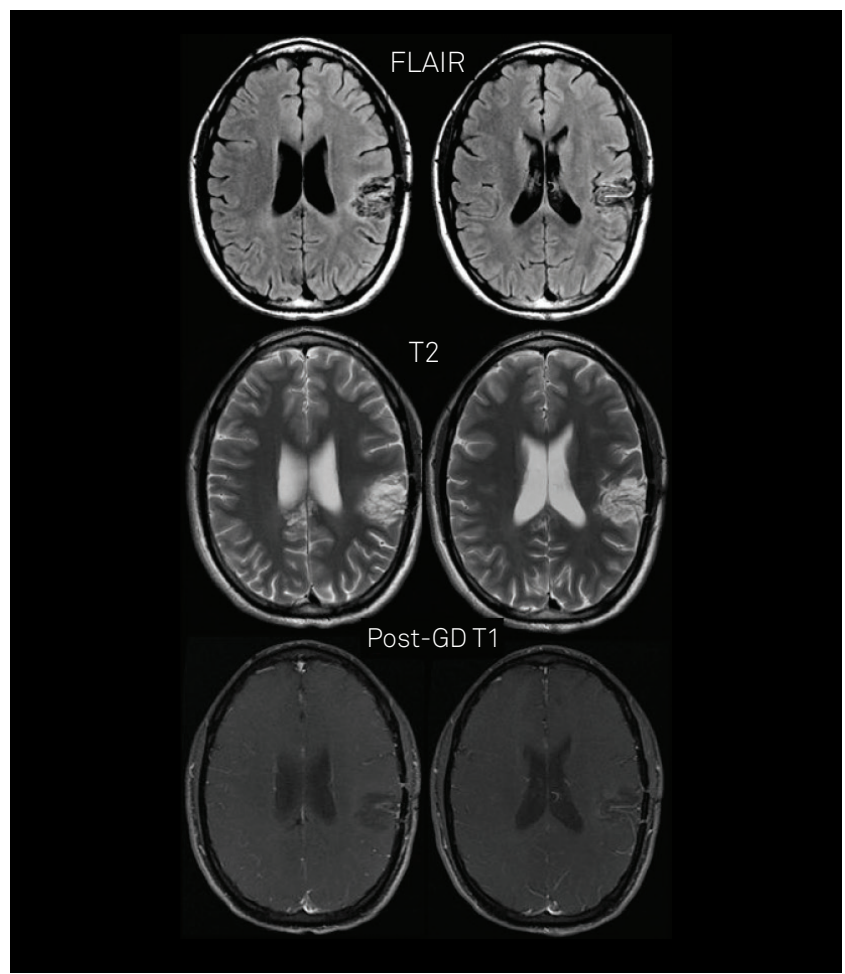

Fig 3. One-year follow-up magnetic resonance imaging. The patient was asymptomatic. Sequelar lesions were detected, without enhancement or mass effect. 
suggest the diagnosis of PLACNS, an immunosuppressive therapy is indicated ${ }^{4,10,11}$.

The studied patient presented the pseudotumoral form of PLACNS with MRI abnormalities, negative DSA, and positive biopsy. One-year-follow-up showed complete resolution of symptoms and MRI improvement, without contrast enhancement.

PLACNS diagnosis is challenging, and it requires clinical history, laboratorial findings, imaging, and eventually a histopathological confirmation.

\section{References}

1. Panchal NJ, Niku S, Imbesi SG. Lymphocytic vasculitis mimicking aggressive multifocal cerebral neoplasm: MR imaging and MR spectroscopic appearance. AJNR Am J Neuroradiol 2005;26:642-645.

2. Kraemer M, Berlit P. Primary central nervous system vasculitis: clinical experiences with 21 new European cases. Rheumatol Int 2011;31:463-472.

3. Qu SB, Khan S, Liu H. Primary central nervous system vasculitis mimicking brain tumour: case report and literature review. Rheumatol Int 2009;30:127-134.

4. Salvarani C, Brown RD Jr, Calamia KT, et al. Primary central nervous system vasculitis: analysis of 101 patients. Ann Neurol 2007;62:442-451

5. Volcy M, Toro ME, Uribe CS, Toro G. Primary angiitis of the central nervous system: report of five biopsy-confirmed cases from Colombia. J Neurol Sci 2004;227:85-89.
6. Appenzeller S, Faria AV, Zanardi VA, et al. Vascular involvement of the central nervous system and systemic diseases: etiologies and MRI findings. Rheumatol Int 2008;28:1229-1237.

7. Myung J, Kim B, Yoon BW, et al. B-cell dominant lymphocytic primary angiitis of the central nervous system: four biopsy-proven cases. Neuropathology 2010;30:123-130.

8. Miller DV, Salvarani C, Hunder GG, et al. Biopsy findings in primary angiitis of the central nervous system. Am J Surg Pathol 2009;33:35-43.

9. Campi A, Benndorf G, Filippi M, et al. Primary angiitis of the central nervous system: serial MRI of brain and spinal cord. Neuroradiology 2001;43:599-607.

10. Noskin O, Libman R, Mayer S, Canoll P. Multifocal hemorrhagic vasculopathy: possibly a manifestation of central nervous system vasculitis. J Stroke Cerebrovasc Dis 2006;15:43-47.

11. Elbers J, Halliday W, Hawkins C, et al. Brain biopsy in children with primary small-vessel central nervous system vasculitis. Ann Neurol 2010;68:602-610. 